\title{
Values Research and Education by Yi-ological-Systemic-Typological Method in Integration Context
}

\author{
Tran Ngoc Them \\ Ho Chi Minh City National University
}

\begin{abstract}
The study of values in the world at present almost follows Western theories and techniques. This is a matter of course in the field of science - technology, but it turns to be much more complicated in the field of social sciences and humanities, because this area is heavily dependent on particular nationalities. Furthermore, the most commonly used in the value research methodology is questionnaire, and using a questionnaire to study values is still restrictive. To overcome this disadvantage, we have developed a Yi-ological-Systemic-Typological method to use mostly in studying values. According to Yi-ological method, value education helps learners to recognize values among non-values, non-values among values. According to Systemic method, it helps learners see the changing of values over the time, the close relationship and interaction between values with non-values. Value education according to Typological method helps learners recognize the similarities and differences between cultures, both apart and close ones.
\end{abstract}

Keywords: values research, values education, Yi-ological method, systemic method, typological method

\section{Integration-Current Situation}

The term "integration" (whether in Western languages, Chinese, or Vietnamese) has the sense of equality and parity ("to integrate into a whole"). Only with equal and fair status can integration achieve the ideal purposes of sympathizing, understanding, and complementing good values to all members.

However, the current situation of international integration is different. The participants are integrating with different starting points in terms of natural resources, population, economy, science-technology, and management capacity. The only thing though different but equally valued is the system of values and culture. In other words, integration theoretically should be equal but actually not. There exist two paradoxes.

The first paradox is that developing countries, which are poor in economy, under-developed in technology and weak in management (a lower starting point), are rich in natural resources and have high population. Meanwhile, developed countries have limited population and are poor in natural resources (they might have exploited them all or have policies to reserve them). Consequently, in the deviated integration, countries with lower starting points are over-exploited in natural resources and labor but receive inadequately valuable and unsustainable economic efficiency. In other words, these countries are suffering from disadvantages.

The second paradox lies in the deviated integration, i.e., countries with higher starting points (developed

Tran Ngoc Them, Prof., Dr.Sc., Director of Centre for Theoretical and Applied Culturology, University of Social Sciences and Humanities, Ho Chi Minh City National University, Vietnam; main research fields: Culture Studies, Philosophy of Culture, Vietnam Culture, Northeast Asia Culture, and Theoretical Linguistics. 
countries) play as models for the rest in all aspects, including the models of values, value research, and value education despite the view that different cultures and value systems of members should be considered equal. Economical and social changes of developing countries according to Western models have been causing some changes in values and value systems, adopting some Western elites. This is a very complicated situation. Without a clever management, then, the multi-facet influence of developed countries on others can easily result in deviated integration, i.e., those with low starting points can easily suffer from value confusion.

\section{Value Research-Current Situation}

\subsection{Commonly Used Methods in Value Studying}

Value education is based on the results of value study. The study of values in the world at present almost follows Western theories and techniques. While the use of Western theories and techniques is not strange, even a matter of course, in the field of science-technology, it turns to be much more complicated in the field of social sciences and humanities. This complexity comes from many causes.

Firstly, this area is heavily dependent on particular nationalities. Due to great differences in cultural traditions, personalities, and nationalities, in many cases, the same things, phenomena, qualities can be viewed contradictorily. For example, while Western people consider "individual" as "independent" or "brave" (a value), Vietnamese consider it as "selfish" (negative meaning) ("He's very selfish"). Another example, while Vietnamese consider "flexible" as "adaptable" (a value), to Westerners, "flexible" means "easy to be adjusted, ordered, and convinced" (non-value).

The one-way application of the theory generalized from Western practice to all mankind can cause lasting misconceptions. For example, while nearly the whole world consider "truth-faithfulness-beauty" as the three typical universal values of mankind, actually only "truth" is the universal value and "faithfulness" and "beauty" are sub-values, contradicting content against appearance, society against individual, quality against quantity. On the other hand, this trio is just the typical values of Western culture since East-Asians have their own ones (welfare-fortune-life).

Secondly, Western research methodology in Social Sciences and Humanities is greatly influenced by that of Natural Sciences and Technology. The most commonly used methodology is questionnaire. The questionnaires of R. Inglehart, G. Hofstede, S. Schwartz... being globally carried out have the advantage of providing impressive data and intuitive charts professionally analyzed by the statistical software SPSS, leading to really persuasive conclusions.

\subsection{The Restrictions of Questionnaire Method in Value Studying}

In fact, using a questionnaire to study values is still restrictive.

Firstly, with this approach, most of the questions are made not to study values but to study the awareness of values. Questions like "The competition between employees often brings more harm than good: (a) Totally agree; (b) Agree; (d) No idea; (d) Disagree; (e) Totally disagree" (question B54 of Hofstede) always ask people what they think about something but do not ask them if it does exist or not. Therefore, "value" has been misunderstood for "awareness of value." Real values exist unconsciously, emotionally and through action, not through words.

Secondly, these questionnaires were compiled on the basis of Western practices, using the Western concepts. Then, the questionnaires were translated into different languages with negligible adjustments. Some 
authors have studied and made some revisions on the overseas questionnaires but still cannot get out of its control. This method has ignored cultural differences of different areas.

Thirdly, besides not taking into account the cultural differences of different areas, a survey with questionnaire also ignores the differences in subjects' nationalities. For example, when applied to Vietnam, this method gives misleading results. This is because Vietnamese are basically face-protecting, impertinent, clever, self-decisive, and mercenary in communication; they, therefore, do not tell the truth. Questioned by Hồ Sĩ Quý $(2006,17)$ "Why do you support your children to school?", 70.4\% people in the survey chose the option "For them to become helpful to society" while in reality there are surely many of them considered their number one goal is not so but for the children "to gain status and position in society," "to make money," "to have stable jobs," or "to escape from manual labor." Our survey in 2014 with 5,604 people showed that $81 \%$ of Vietnamese are deceitful with words not going hand in hand with actions (Trần Ngọc Thêm 2016, 418-21).

Fourthly, surveys with questionnaires cannot reflect the traditional values over time. R. Inglehart's method to study how values change over generations (Inglehart et al. 1998) could not fix this defect. The differences in values over the time in general and the differences between traditional and modern values in particular should be made with the gap of a century or at least several decades. Meanwhile, the gap between generations in R. Inglehart's survey was only a decade. Therefore, it is wrong to base on the data of G. Hofstede that Western countries have low or relatively low power distance (Hofstede 2012) to conclude that "democracy" is Western traditional value. Not until the beginning of the twentieth century did Western women have to fight hard to get a job and receive equal pay with men. Also, not until the late 1960s-1970s did the revolutions gender and sexuality take place.

Due to the above limitations, data from these surveys do not fully reflect reality. Somewhat biased and misleading interpretation can bring about not only useless orientation and value education but also value confusion in countries with low starting points. Thus, we do not deny the usefulness of questionnaire, but neither to promote it too much nor to over-use it.

\section{Studying Values by Yi-ological-Systemic-Typological Method}

To overcome this disadvantage, we have developed a Yi-ological-Systemic-Typological method to use mostly in studying values.

\subsection{Systemic Method}

Systemic method is a common achievement. Many researchers claim to use this method, but in fact, not everyone is successful. For example, many researchers have discussed the value of "collectivism"- -individualism," but most of them just mentioned their systematic opposition and no one has ever put it in a series of related concepts such as cohesion, dependence, freedom, solitude, stability, development... Meanwhile, "collectivism" proves to have many different meanings in different sub-systems: family, village, society, etc. All of them constitute a hierarchical system. Thoroughly understanding the relationship between the elements in each sub-system and between sub-systems allows researchers to recognize and to determine the values/non-values of each element and each sub-system.

\subsection{Typological Method}

The concept of "type" is well-known, but the Typological method is not so popular. It can only be used effectively when combined with the Systemic method. The process of this method can be attributed to four steps: 
(1) Classifying the subjects into groups;

(2) Selecting the type of system used as a standard;

(3) Mapping the relationship between the subjects with the selected type of system;

(4) Using the typical characteristics of the type selected in step (2) to describe the corresponding elements after mapping and checking, adjusting results.

The typological method in studying values and value systems follows the rule: The more detailed the division is, the more accurate the result is, and the less generic the features are. Dichotomy is too general while quartile and quintile are too detailed; trident is probably the most suitable one.

\subsection{Yi-ological Method}

Yi study is a popular concept, but Yi-ological method applied in scientific research is new (need to be explained). Yi refers to the movement, fluctuation. Yi-ology is the general principle of movement and advanced thinking. The foundation of Yi study, Yi-ology, and Yi-ological method is the philosophy of yin and yang. The philosophy of yin and yang was primarily formed on the basis of two-side thinking in Southeast Asia, finished in ancient China, then popularized in Northeast Asia and Southeast Asia (Tran Ngoc Them 2013).

The philosophy of yin and yang operates in three main principles: co-existence (yin exists in yang and yang exists in yin), interchangeability (yin comes from yang and yang comes from yin), and neutralization (yin and yang are neutral at the contact). The Yi-ological method can be understood as a process of using the characteristics and rules of yin and yang philosophy in particular and Yi study in general, i.e., co-existence, interchangeability, and neutralization to consider elements in their situation of closely connected, continuously distributed, and restlessly moving within a unit.

Applying Yi-ological method in studying "collectivism" as a Vietnamese value "individual" as a Western value, we can discover many interesting things.

According to the principle of interchangeability, too much collectivism can produce individualism. High collectivism makes each village a domain. Vietnamese people getting out of their village act as individuals, refusing to co-operate with others. Meanwhile, too much individualism may turn out to be the collectivism. The West appreciates individualism, so people always work together for mutual benefits.

According to the principle of co-existence, individualism exists in collectivism: There was a great solidarity in Vietnamese villages for each member or family to enjoy security and stability. Similarly, collectivism exists in individualism: Western people had the maximum degree of freedom for the ancient nomadic society to easily mobilize and for the present industrial society to develop quickly.

According to neutralization, neither too much individualism nor too much collectivism is good. It's better to combine individualism and collectivism harmonically, to ensure that both the individual and society can be developed in a sustainable way.

\subsection{Yi-ological-Systemic-Typological Method in Studying the Pair of Values}

\section{"Individualism-Collectivism"}

To promote efficiency, all the three methods: Yi-ological, Systemic, and Typological should be closely coordinated together to make a new single one: Yi-ological-Systemic-Typological method.

Using Yi-ological and Typological methods, we have a universal system with three elements: the Yin-oriented culture, the Yang-oriented culture, and the Intermediate culture. 
Regarding to region, Southeast Asian countries with rice farming are typical for Yin-oriented culture. The West with ancient nomadic animal husbandry and leading role in economy, science, and technology today is typical for Yang-oriented culture. Meanwhile, Northeast Asia with both static and dynamic characteristics is typical of the type of Intermediate culture. Thanks to both static and dynamic characteristics, Northeast Asian countries have promoted their advantages of both types of culture to develop (Singapore with more than $74 \%$ of the population being Chinese can be seen as a Northeast Asian country in Southeast Asia).

Using Yi-ological-Systemic-Typological method to study the pair of values "individualism" and "collectivism," we can see that "individualism" is most suitable for the development of Yang-oriented culture of the West. Similarly, "collectivism" is most suitable for the stability of the Yi-oriented culture of the Southeast Asian. As for the intermediate type of culture of Northeast Asian, family/clan is respected for both the development and the stability. Although the West appreciates individualism, it is not the same among countries. America has the highest index in individualism while North European countries are more social than the rest of European. Individualism, hence, can be called "social individualism."

By this methodology, we can build up models of universal values from the relevant values of cultural types. For example, from the analysis related to the concept of "Individualism-Collectivism" mentioned above, we can build up a model of universal values for "Individualism-Collectivism" showed in Figure 1. In particular, collectivism is the typical value of Southeast Asia, family/clan is the typical value of Northeast Asia, social individualism is the typical value of Northern European, and individualism is the typical value of American.

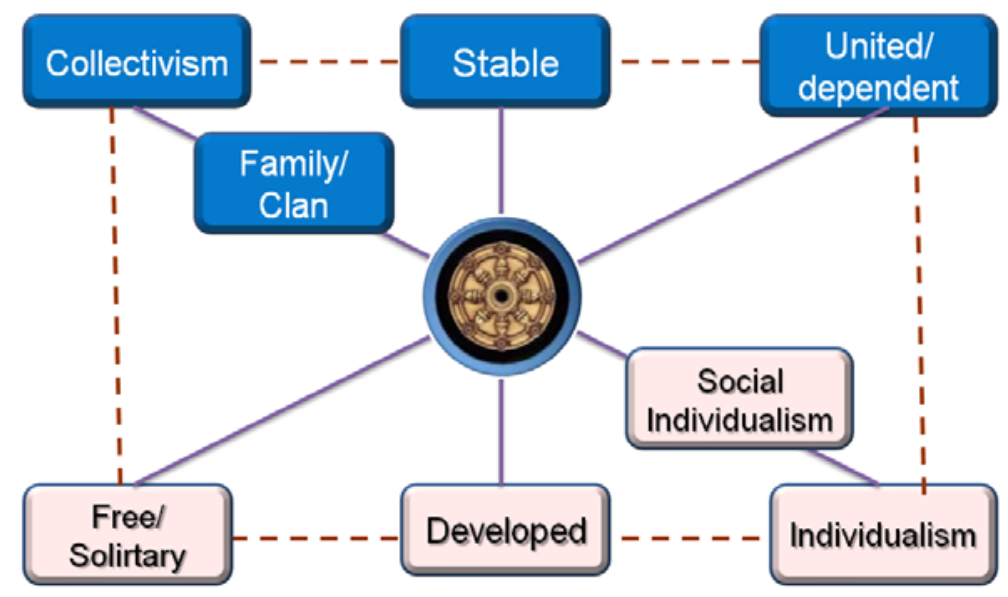

Fig. 1. Universal model for the pair of value “Collectivism-Individualism”.

With this type of model, it is important to identify the four contradicting concepts located in the four corners. The related remainders will be distributed in six axes (four sides of the rectangle and two diagonals). The central location is for the value that meets all the requirements. It can be considered as the common value for all cultures. Therefore, in fact, this ideal value is unattainable to any specific culture; and rarely it is given a particular name in any language.

Though it is a universal model of values, the terms for this model should be from the same language. Then, these terms with their senses reflect that particular culture. Still, the model is universal; with the same model, different cultures reveal different values. 


\subsection{The Role of Each Component in Yi-ological-Systemic-Typological Method}

The Typological method helped researchers to study values based on different traditions, different nationalities' characteristics. Based on the findings, researchers find out the typical features of the value system and determine the values to be added. Meanwhile, based on the yin-yang philosophy, the Yi-ological method helps to evaluate the point in a reasonable manner, balancing tradition and modern, the East and the West, values and non-values. The Systemic method helps to combine elements logically and coherently.

\section{Educating Values by Yi-ological-Systemic-Typological Method}

Considering value education in terms of "individualism-collectivism," we can see that Vietnamese educate values in a collective way. The most highly appreciated community in education is school. School is the bearer of all the weaknesses of Vietnamese people. Schools even innocently take all responsibilities, including the responsibility for teaching life skills. Meanwhile in America, children have the right not to go to school; parents have the right to educate their children at home (home schooling).

In contrast, individualism in Vietnam is entirely overlooked. In the family, parents have a habit of subsidizing, thinking, and doing everything for their children. Many elderly believe that they need to think for, to guide and even to do things for their 40-50 years old children. Some elderly are found caning to their neighbors to apologize for their children's faults.

At school, children are taught exactly the same, to follow the same patterns. "Good child" (to obey, not to argue against parents) and "excellent student" (to remember lessons) are the two values for generations in Vietnamese education. In society, leaders generally prefer subordinates to be inferiors and to obey them without questions. People often have the habit of copying the behavior of their fellows. The Ministry of Education is always concerned with preparing common curricula, composing common textbooks, issuing common enrollment, and graduation exams, imposing cut-off scores for the whole country...

Even the government has the thought of thinking, talking for and acting for people. Students with strange personalities and thoughts are often ranked last and hated. Individuals with anything unusual are often blamed by the society. There was a moan by the ancient great Vietnamese poet Nguyen Du: "Talents produce bad lucks."

Applying Yi-ological-Systemic-Typological method, value education in Vietnam must first get out of the control of community. A fully developed Vietnamese must be a harmonious combination between individualism and collectivism according to Yi-ology, i.e., "individualism exists in collectivism and collectivism exists in individualism." There are many levels between individualism and collectivism. Education is not the responsibility of the three "family-school-society." It should be the effective coordination of the five Individual, Family, School, Society, and Government.

Individuals not only receive value education from families, schools, and society but also need to take responsibilities. The first is to educate themselves. Right from kindergarten, each child should be taught to be responsible for his own decision, not to rely on others. Self-study is always the most effective. The second is to feedback to each element, making the whole system better. The community should totally respect and encourage the development of each child. 
Along with the maturity of people, the relationship between individuals and the remaining elements will change gradually: Individual's roles will increase while the roles of family, school, and society will decrease. However, the roles of government remain stable, helping people confirm and develop themselves in the right way; helping school, society (and family) conduct their own functions (Figure 2).

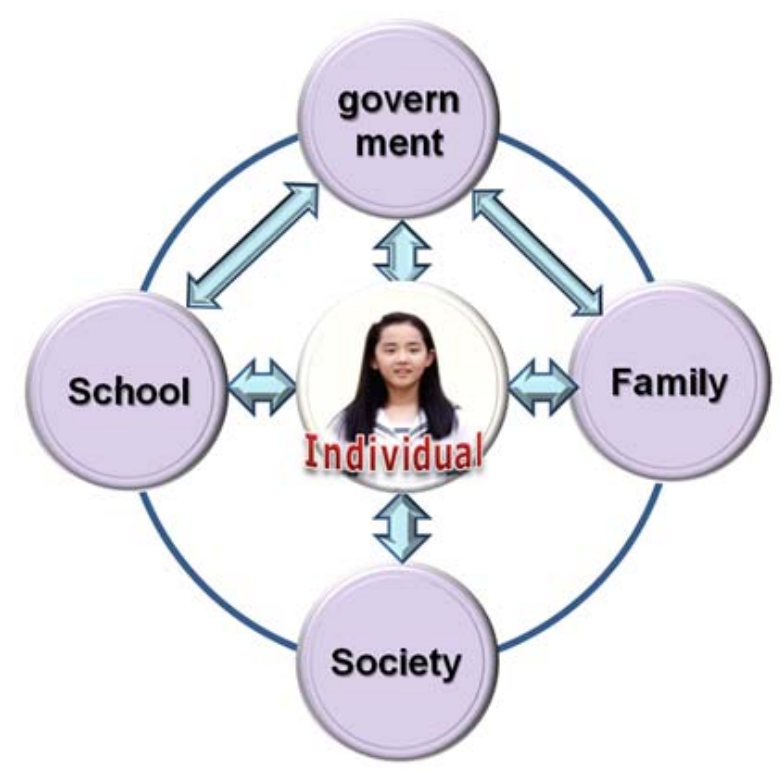

Fig. 2. "Collectivism-Individualism" in value education.

\section{Conclusion}

According to Yi-ological method, value education helps learners to recognize values among non-values, non-values among values, as well as the neutralization nature of contradicting pairs of values. Values education according to Systemic method helps learners see the changing of values over the time, the close relationship and interaction between values and between values with non-values. Value education according to Typological method helps learners recognize the similarities and differences between cultures, both apart and close ones. Yi-ological-Systemic-Typological method does not say "no" to quantitative method but use it to supplement and to verify its results.

\section{Works Cited}

Hofstede G. The Hofstede Centre. Helsinki, Finland: 2012. <http://geert-hofstede.com>.

Hồ Sĩ Quý. Về giá trị và giá trị châu Á (In terms of value and Asia's values). H.: NXB Chính trị Quốc gia, 337 tr., 2006.

Inglehart R., et al. Human Values and Belief: A Cross-Cultural Source Book: Political, Religious, Sexual and Economic Norms in 43 Societies: Finding from the 1990-1994 World Value Survey. USA: The University of Michigan Press, 534 p., 1998.

Trần Ngọc Thêm. Hệ giá trị Việt Nam tù truyền thống đến hiện đại và con đương tới tuoong lai (Vietnam values system from traditional to modern and future path). Tp.HCM: Nxb Văn hóa - Văn nghệ, 589 tr., 2016.

---. "Vietnam Origin of the Philosophy of Yin and Yang and Its Impact on the Vietnamese Character." Dà yì jí sī (The Proceedings of the International Symposium on the Early Formation and Evolution of the Yi-ology). Ed. Liu Dajun. Shanghai Science and Technology Literature Publishing House, 2013. 466-73. 